\title{
L-deprenyl, A Selective MAO-B Inhibitor
}

\author{
Raymond W. Lam, MD \\ University of British Columbia
}

Follow this and additional works at: https://jdc.jefferson.edu/jeffjpsychiatry

Part of the Psychiatry Commons

Let us know how access to this document benefits you

\section{Recommended Citation}

Lam, MD, Raymond W. (1987) "L-deprenyl, A Selective MAO-B Inhibitor," Jefferson Journal of Psychiatry. Vol. 5 : Iss. 2 , Article 6.

DOI: https://doi.org/10.29046/JJP.005.2.003

Available at: https://jdc.jefferson.edu/jeffjpsychiatry/vol5/iss2/6

This Article is brought to you for free and open access by the Jefferson Digital Commons. The Jefferson Digital Commons is a service of Thomas Jefferson University's Center for Teaching and Learning (CTL). The Commons is a showcase for Jefferson books and journals, peer-reviewed scholarly publications, unique historical collections from the University archives, and teaching tools. The Jefferson Digital Commons allows researchers and interested readers anywhere in the world to learn about and keep up to date with Jefferson scholarship. This article has been accepted for inclusion in Jefferson Journal of Psychiatry by an authorized administrator of the Jefferson Digital Commons. For more information, please contact: JeffersonDigitalCommons@jefferson.edu. 


\title{
L-deprenyl, A Selective MAO-B Inhibitor
}

\author{
Raymond W. Lam, M.D.
}

\section{INTRODUCTION}

Monoamine oxidase inhibitors (MAOIs) are now recognized as effective medications in the treatment of major depression (1). However, their clinical use has been limited by the risk of severe hypertensive reactions to oral tyramine challenge. Prevention of this so-called "cheese effect" requires adherence to diet restrictions that can lead to problems with patient compliance to MAOIs.

$\mathrm{L}$-deprenyl is a selective MAO-B inhibitor that is reportedly free of the "cheese effect" (2). This review will discuss the clinical and theoretical importance of this interesting drug.

\section{PHARMACOLOGY}

In 1968, Johnstone reported multiple forms of the monoamine oxidase (MAO) enzyme (3). MAO-A, an enzyme inhibited by the MAOI clorgyline, is responsible for selectively metabolizing norepinephrine and serotonin. MAO-B, selectively inhibited by deprenyl, preferentially metabolizes phenylethylamine (PEA) and benzylamine, with little effect on the MAO-A substrates. Dopamine and tyramine are metabolized by both types of MAO enzymes. The first generation MAOIs (phenelzine and tranylcypromine) non-selectively inhibit $\mathrm{MAO}-\mathrm{A}$ and MAO-B.

Deprenyl (also known as deprenil or selegiline) is an irreversible MAO-B inhibitor (4). The levorotatory isomer is thought to be more selective of MAO-B inhibition and is the form most thoroughly studied, so that references to deprenyl in this paper refer to l-deprenyl unless otherwise specified. At doses that are selective for MAO-B inhibition (10-30 mg/day), studies of deprenyl show no evidence of hypertensive reactions to $200 \mathrm{mg}$ of ingested tyramine, a considerably larger amount than found in the usual diet (5). Dosages of greater than $30 \mathrm{mg} /$ day of deprenyl leads to partial MAO-A inhibition, but never to the extent of the non-selective MAOIs.

The mechanism for deprenyl's lack of cheese effect may be that, despite the total MAO-B inhibition, there continues to be substantial tyramine deamination

This article was written when the author was a senior resident in the Department of Psychiatry at the Health Sciences Centre Hospital, University of British Columbia. He is currently a Research Fellow at the University of California at San Diego. 
by intestinal MAO (7), which is predominantly MAO-A (6). Dopamine in the human brain is metabolized mostly by MAO-B (8), and platelet MAO is also of the B-type (9). Platelet MAO-B inhibition has been used as a measure of MAO-B inhibition in the brain (10), but recent work casts doubt on the correlation between platelet and brain MAO activity (11). A promising new technique to measure in vivo brain $\mathrm{MAO}$ activity utilizes positron emission tomography and ${ }^{11}$ C-labeled selective MAOIs (12).

As expected, deprenyl administration results in a sharp rise in urinary PEA, and this too can be used to measure the degree of central MAO-B inhibition. The ingestion of large amounts of PEA also has no significant pressor response in patients taking deprenyl (5).

Deprenyl has other biochemical effects in addition to MAO inhibition. It demonstrates some blockade of norepinephrine and dopamine reuptake and inhibition of norepinephrine release (4). Because deprenyl is metabolized to methamphetamine and amphetamine in humans (13), it has some dopamine releasing properties.

\section{CLINICAL TRIALS}

\section{Parkinson's Disease}

MAOIs have been used in the treatment of Parkinson's disease in conjunction with L-dopa/carbidopa. However, their use has again been limited due to the disabling side effects of hypotension and tyramine crises.

The clinical efficacy of deprenyl as an adjunct to standard antiparkinsonian treatment is well documented (14). The mechanism of action is now thought to be inhibition of striatal dopamine oxidation by MAO-B (15), thereby leading to increased availability of dopamine, as opposed to a dopamine releasing mechanism (ie. by an amphetamine-like action). The dosages used, usually 10-20 $\mathrm{mg} /$ day, have produced no adverse effects and no hypertensive crises (16). Because deprenyl potentiates the action of L-dopa, the dosage of L-dopa can often be lowered when deprenyl is started. Deprenyl may be of particular benefit in the "off" phase of the on-off phenomenon seen in advanced stages of Parkinson's disease that is now recognized as part of the disease process rather than a tolerance effect to long-term administration of L-dopa (17). It is also more likely to benefit the "benign" forms of Parkinson's disease and is less effective in the malignant subtypes of this disorder.

Long-term deprenyl use in patients with Parkinson's disease suggest that use of deprenyl may be associated with prolonged life expectancy, an effect not seen in other antiparkinsonian treatments $(16,18,19)$. Deprenyl has also been shown to prevent the striatal neurotoxicity of MPTP (20) in animal models of Parkinson's disease, suggesting that it may prevent progression of the disease at some level. 


\section{Major Depression}

Clorgyline, the selective MAO-A inhibitor, has been shown to have significant antidepressant activity. Previous double blind studies found it to be as effective as imipramine (21). However, because clorgyline also has the cheese effect, it held no advantage over previous MAOIs.

Since MAO-B inhibition is free of the cheese effect, it would be of clinical interest if MAO-B inhibitors were effective antidepressant drugs. Early open studies of deprenyl showed an antidepressant effect, but these studies used higher, non-selective dosages of the MAO-B inhibitor as well as racemic forms of deprenyl (22). Negative results were obtained in one controlled study where pargyline, a partially selective MAO-B inhibitor, was shown to be significantly inferior to clorgyline in the treatment of major depression (23).

There are only two controlled studies of deprenyl's efficacy in depression. Mendlewicz and Youdim (24), in a double blind study of 27 patients with RDC-defined major depression, found a significantly greater number of patients who responded to $15 \mathrm{mg} /$ day of deprenyl $(10 / 14$ patients with $<50 \%$ of pretreatment Hamilton Rating Scale [HRS] score, $7 / 14$ patients with $<25 \%$ of pretreatment HRS) as compared to placebo (2/13 and $0 / 13$ patients respectively).

In contrast, Mendis et al conducted a double blind trial of deprenyl versus placebo in 22 patients with "mild to moderate" unipolar depression (25). They showed no differences between $20 \mathrm{mg}$ /day of deprenyl and placebo in the Hamilton scores, self-rating scales, and global clinical rating scales. Although diagnostic criteria were not specified, this group's experience was that similarly diagnosed patients showed a $50 \%$ marked response to traditional tricyclics compared to the $20 \%$ response of deprenyl and placebo reported in this study.

In an open trial of deprenyl, Mann et al (26) reported that $16 / 25$ RDC-defined depressed patients responded to $10-20 \mathrm{mg} /$ day of deprenyl (response $=<50 \%$ pretreatment HRS).

\section{Atypical Depression}

MAOIs have traditionally been thought to be most effective for so-called "atypical depressions" (27), and some evidence exists that perhaps deprenyl is more effective in this sub-type of depressive illness.

Mendlewicz and Youdim noted a non-significant trend of their deprenyl responders have "atypical symptoms" (neurotic, anxious and somatic features) (17).

Mann et al in their open study $(26)$ showed a trend $(p<0.10)$ for more deprenyl responders among "nonendogenous" depressives as defined by the Newcastle Scale (10/12 non-endogenous vs 6/13 endogenous). Both groups showed significant reduction of Hamilton scores after 21 days of treatment but the non-endogenous group responded after only 7 days. The non-endogenous 
group also had lower HRS scores overall, but it is unclear from their data if this was statistically significant. Fewer unipolar endogenous depressives seemed to respond compared to bipolar, but not at statistically significant levels.

In an open trial of deprenyl in atypical depressives, Quitkin et al (28) found that $10 / 17$ responded (much improved or better on the CGI). Compared to a placebo group in a parallel double-blind study of phenelzine-imipramineplacebo, however, there was only a trend to superiority of deprenyl $(p<0.10)$. Of the 10 responders, 9 required doses of $30 \mathrm{mg} /$ day, which the investigators felt was perhaps not selective for MAO-B alone.

\section{SUMMARY OF CLINICAL TRIALS}

While it is clear that deprenyl is an effective antiparkinsonian drug, its antidepressant efficacy is still in question. The two controlled studies show conflicting results while open studies have been more encouraging, particularly in the treatment of atypical, non-endogenous depression. It should be noted that the two studies showing negative results with MAO-B inhibitors used depressed patients with "endogenous" symptoms, a population which may be less responsive to MAOIs $(23,25)$. Future controlled studies should incorporate subtyping of depression or compare deprenyl to non-selective MAOIs.

\section{PSYCHOBIOLOGY OF DEPRESSION}

If deprenyl is an effective antidepressant, what might be its mechanism of action? Since deprenyl is metabolized to methamphetamine and amphetamine, and because deprenyl is reported to have a faster onset of action than other MAOIs, one might suspect that its antidepressant effect is simply due to amphetamine. L-deprenyl is presumably metabolized to l-amphetamine, which is thought to be less euphoria-producing than its isomer, d-amphetamine (29). In Quitkin et al's study (28), 7/8 patients showing pre-treatment dysphoric responses to amphetamine administration responded to deprenyl, while only $3 / 7$ showing euphoria responded to deprenyl. Thus, it may not be the amphetamine-like action of deprenyl that is responsible for its antidepressant effect. Another interesting finding was that not only did deprenyl increase urinary PEA, but it also significantly decreased urinary MHPG when no effect would be expected (30). In addition, those patients with the lowest baseline MHPG levels appeared to be the ones to respond to deprenyl. Thus, deprenyl's antidepressant action may be mediated through biochemical effects other than the MAO-B inhibition.

Mendlewicz and Youdim (24) found that deprenyl responders had a greater degree of platelet MAO-B inhibition when compared to non-responders. However, other investigators have shown that inhibition of greater than $80 \%$ of platelet MAO-B consistently occurs even with short term administration of 10 mg of deprenyl (31). 
What if deprenyl is not an effective antidepressant? Knowing that clorgyline is effective, this could mean that MAO-A inhibition is the essential mechanism for the antidepressant effect. This hypothesis has been forwarded by several investigators $(23,25)$, and is more consistent with the monoamine hypothesis of depression since norepinephrine and serotonin, the neurotransmitters traditionally linked to the psychobiology of depression, are metabolized by MAO-A. Some studies show that only higher doses of deprenyl are effective against depression, when MAO-A may also be inhibited (28). If MAO-B inhibition was the critical factor, then one would expect lower doses of deprenyl, producing almost complete platelet MAO-B inhibition (31), to be equally effective. Other investigators have suggested that the antidepressant effect of MAOIs shares the same mechanism as the cheese effect, postulating that the effect is mediated through enhancement of central norepinephrine release due to trace amounts of tyramine acting on central synapses (25).

\section{CONCLUSION}

L-deprenyl, a selective MAO-B inhibitor, is an effective adjunctive treatment for Parkinson's disease. However, evidence that selective MAO-B inhibitors are as effective as non-selective MAOIs in the treatment of depression remains inconclusive, although there is suggestion that deprenyl may be effective in "atypical depression." Deprenyl is not yet commercially available, but further studies are warranted because the lack of a cheese effect confers a significant advantage over other MAOIs that would make deprenyl an important addition to our antidepressant armamentarium. Furthermore, by using selective MAO inhibitors such as clorgyline and deprenyl as psychopharmacological probes we can glean further insights into the psychobiology of depressive disorders.

\section{REFERENCES}

1. Pare CMB: The present status of monoamine oxidase inhibitors. $\mathrm{Br} J$ Psychiatry 146:576-584, 1985

2. Mann JJ, Aarons SF, Frances AJ et al: Studies of selective and reversible monoamine oxidase inhibitors. J Clin Psychiatry 45:62-66, 1984

3. Johnstone JP: Some observations upon a new monoamine oxidase inhibitor in brain tissue. Biochem Pharmacol 17:1285-1297, 1968

4. Knoll J: Deprenyl (selegiline): the history of its development and pharmacological action. Acta Neurol Scand Suppl 95:57-80, 1983

5. Elsworth JD, Glover V, Reynolds GP et al: Deprenyl administration in man: A selective monoamine oxidase B inhibitor without the "cheese effect." Psychopharmacology 57:33-38, 1978

6. Squires RF: Multiple forms of monoamine oxidase in intact mitochondria as characterized by selective inhibitors and thermal stability - a comparison of eight 
mammalian species, in Monoamine Oxidases, edited by Costa $\mathrm{E}$ and Sandler M. New York, Raven Press, 1972, p 355-370

7. Garcha G, Imrie PR, Marley E et al: Distribution and effects of intestinally administered 14C-tyramine in cats, modified by monoamine oxidase inhibitors. $J$ Psychiat Res 17:75-92, 1982/83

8. Glover V, Sandler M, Owen F et al: Dopamine is a monoamine oxidase B substrate in man. Nature 265:80-81, 1977

9. Donnelly $\mathrm{CH}$, Murphy DL: Substrate- and inhibitor-related characteristics of human platelet monoamine oxidase. Biochem Pharmacol 26:853-858, 1977

10. Fowler CJ, Tipton KF, Mackay AVP et al: Human platelet monoamine oxidase: a useful enzyme in the study of psychiatric disorders? Neuroscience 7:1577-1594, 1982

11. Young WF, Laws ER, Sharbrough FW et al: Human monoamine oxidase: lack of brain and platelet correlation. Arch Gen Psychiatry 43:604-609, 1986

12. Fowler JS, MacGregor RR, Wolf AP et al: Mapping human monoamine oxidase A and B with ${ }^{11} \mathrm{C}$-labelled suicide inactivators and PET. Science 235:481-485, 1987

13. Reynolds GP, Elsworth JD, Blau K et al: Deprenyl is metabolized to methamphetamine and amphetamine in man. Br J Clin Pharmacol 6:542-544, 1978

14. Reiderer P, Jellinger K, Danielczyk W et al: Combination treatment with selective monoamine oxidase inhibitors and dopaminergic agonists in Parkinson's Disease: biochemical and clinical observations, in Advances In Neurology, Vol 37: Experimental Therapeutics of Movement Disorders. Edited by Fahn S, Calne DB and Shoulson I. New York, Raven Press, 1983

15. Riederer P, Youdim MBH: Monoamine oxidase activity and monoamine metabolism in brains of Parkinsonian patients treated with l-deprenyl. J Neurochem 46:13591365,1986

16. Birkmayer W, Reiderer P, Ambrozi L et al: Implications of combined treatment with Madopar and L-deprenil in Parkinson's disease. A long-term study. Lancet i:439443,1977

17. Rinne UK, Sirrtola T, Sonninen V: L-deprenil treatment of on-off phenomena in Parkinson's disease. J Neural Trans 43:253-262, 1978

18. Riederer P, Wuketich S: Time course of nigrostriatal degeneration in Parkinson's disease. J Neur Trans 38:277-301, 1976

19. Birkmayer W, Reiderer P, Rausch WD: Neuropharmacological principles and problems of combined l-dopa treatment in Parkinson's disease, in Advances in Neurology, Vol 24: The Extrapyramidal System and its Disorders. Edited by Poirier R. New York, Raven Press, 1979

20. Heikkila RE, Manzino L, Cabbat FS et al: Protection against the dopaminergic neurotoxicity of l-methyl-4-phenyl-1,2,5,6-tetrahydropyridine by monoamine oxidase inhibitors. Nature 311:467-469, 1984

21. Wheatley D: Comparative trial of a new mono-amine oxidase inhibitor in depression. Br J Psychiatry 117:573-574, 1970

22. Varga E, Tringer L: Clinical trial of a new type of promptly acting psychoenergetic agent (phenyl-isopropylmethylpropinyl-HCl, E-250). Acta Med Acad Sci Hung 23:289-295, 1967

23. Lipper S, Murphy DL, Slater S et al: Comparative behavioural effects of clorgyline and pargyline in man: a preliminary evaluation. Psychopharmacology 62:123-128, 1979 
24. Mendlewicz J, Youdim MBH: L-deprenil, a selective monoamine oxidase type B inhibitor, in the treatment of depression: a double blind evaluation. Br J Psychiatry 142:508-511, 1983

25. Mendis N, Pare CMB, Sandler M et al: Is the failure of (-)deprenyl, a selective monoamine oxidase $\mathrm{B}$ inhibitor, to alleviate depression related to freedom from the cheese effect? Psychopharmacology 73:87-90, 1981

26. Mann JJ, Frances A, Kaplan RD et al: The relative efficacy of 1-deprenyl, a selective monoamine oxidase type B inhibitor, in endogenous and nonendogenous depression.J Clin Psychopharmacol 2:54-57, 1982

27. Liebowitz MR, Quitkin FM, Stewart JW et al: Phenelzine vs imipramine in atypical depression. Arch Gen Psychiatry 41:669-677, 1984

28. Quitkin FM, Liebowitz MR, Stewart JW et al: l-Deprenyl in atypical depressives. Arch Gen Psychiatry 41:777-781, 1984

29. Smith RC, Davis JM: Comparative effects of d-amphetamine, l-amphetamine, and methylphenidate on mood in man. Psychopharmacol 53:1-12, 1977

30. Liebowitz MR, Karoum F, Quitkin FM et al: Biochemical effects of 1-deprenyl in atypical depressives. Biol Psychiatry 20:558-565, 1985

31. Simpson GM, Frederickson E, Palmer R et al: Platelet monoamine oxidase inhibition by deprenyl and tranylcypromine: implications for clinical use. Biol Psychiatry 20:680-684, 1985 